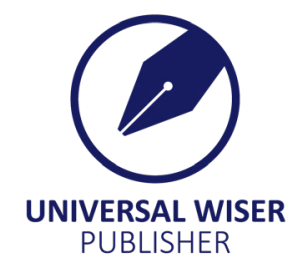

\title{
Relative Clause Formation in Akan Proverbs and Sentences: Similarities and Differences
}

\author{
Isaac Oduro*, Olivia Donkor \\ Department of Languages, Saint Monica's College of Education, Ghana \\ E-mail: isaacoduro1970@yahoo.com
}

\begin{abstract}
This paper discusses relative clause formation in Akan proverbs and normal sentences with particular attention to their similarities and differences. It explores the comparison of the relative clauses in Akan sentences and other specialized genres such as the proverbs. The paper further analyzes the relative clause occurring in both sentence and proverb structures in order to establish sameness and dichotomy in the syntactic uniqueness in both structures. Purposive sampling technique was employed to select the proverbs for this study. In all, twenty-three (23) proverbs were selected for the study. The study adopted the functional grammar approach in the analysis. The study revealed that the relative clause formation in some Akan proverbs and Akan normal sentences has both overt and covert antecedent noun phrases (ANPs). The headless antecedent noun phrase which is seen as a pronominal also undergoes binary mutation in order to account for the antecedent noun phrase and the relativizer which introduces the relative clause. There are also differences in the syntactic positions of the relative clause more especially the sentence structure type. Finally, there is a difference in the syntactic position of the resumptive pronouns in both structures.
\end{abstract}

Keywords: overt, covert, pronominal, headless, antecedent relativizer

\section{Introduction}

The relative clause $(\mathrm{R} / \mathrm{C})$ has been examined universally as a linguistic phenomenon and its occurrence is widely manifest in all the human languages in the world. It has been strongly revealed that, the constitution of the relative clause cross-linguistically occurs in all natural languages in one form or another ${ }^{[51]}$. Having examined the relative clause crosslinguistically, it appears much work has been done by some scholars in the English language and some other languages as far as typological study and analysis is concerned ${ }^{[51,54]}$. A lot of scholars of the Akan language to some extent have done detailed work on Akan normal relative clause ${ }^{[10,47]}$. Oduro ${ }^{[41]}$ highlighted relative clause formations in Akan proverbs drawing attention to headless antecedent noun phrase where the antecedent noun phrase appears to be covert in the structure. These revelations have called for comparison of the relative clause formation in both the Akan normal sentence and Akan proverb structure. The main body of the article is further sectionalized into the following divisions. The first section briefly highlights the background of the Akan language. The second section deals with the theoretical approach that has been used to do the analysis. In the third section, attention has been focused on both Akan proverb structure and Akan normal sentence. Section four deals with R/C formation in both Akan normal sentence and Akan proverb structure whereas section five treats analysis of both the similarities and the differences of the two structures. The penultimate section will talk about the findings of the study followed by the conclusion.

\section{Background of the Akan lannguage}

The Akan language is a subset of the language family called Volta-Comoe group found along the West African coast ${ }^{[13]}$. In terms of the language family tree, Akan also belongs to Kwa language which is made up of three main mutually intelligible dialects comprising, Akuapim, Asante and Fante ${ }^{[13]}$. Other dialects of Akan language are: Akyem, Assin, Bono, Akwamu, Denkyira, Wasa, Kwawu, Sefwi ${ }^{[13,44]}$. Out of the sixteen regions in Ghana, the Akan language is spoken in ten of the regions. Akan is, in fact, one of the most popular spoken languages in Ghana. Akan language is mutually intelligible in relation to other dialects of the same languages. As a result of that, considerable numbers of Ghanaians also use it as

This is an open-access article distributed under a CC BY license

(Creative Commons Attribution 4.0 International License)

https://creativecommons.org/licenses/by/4.0/ 
their second language of communication in commerce and trade ${ }^{[13]}$. It is estimated that the indigenous Akans constitute approximately $47.5 \%$ of the entire population of Ghana ${ }^{[22]}$.

\section{Theorectical framework of the study}

The study uses the functional grammar approach which was originated by Halliday ${ }^{[25]}$. This same theoretical framework has been adopted by $[13,17,24,47,53]$ in their various write-ups. This functional grammar model stresses on three key functions. These are, 'representational function', 'interpersonal function', and 'textual meta-function'. The writers only adapt the second and third components in this work. Whiles the representational function interprets the world around us, interpersonal functions streamlines the interactions that go on to bring changes in things around us. The functional approach has been used to make description of the communicative function of each of the lexical items forming part of the relative clause. The 'textual' meta-function comes in the picture when messages are organized so as to enable representation and interaction. The 'textual' meta-function links all the linguistic units or elements otherwise called 'text' in a specific structure because they have the edge to assume different functions. Again, the 'textual' meta-function ensures that, the linguistic items in a particular structure should not be treated or considered in isolation but having links or relation to other elements in the structure under consideration. In this regard, the 'textual' meta-function of the functional grammar will be of immeasurable assistance to the writers to be able to analyze the relationship among the linguistic units of the Relative clause and the whole structure of which the relative clause forms part. In order to show similarities and differences in both structures, the study also adopts comparative approach to perform cross-structural analysis of the normal clause and that of relative clause in a specialized genre under consideration.

\section{Proverbs: definition and functions}

Over the years, scholars from different disciplines of learning have found it extremely difficult to assign a single universal definition to proverbs. As result of this, Kindstrand ${ }^{[28]}$ cited in [35] believe this failure has always been a headache to many a paremiologist. The above assertion comes as no surprise as there are many reasons which may have accounted for the failure. Careful observations reveal that the socio-cultural diversity, linguistic background, sociogeographical experiences couple with the orientations of people have made it very uneasy to have such common definition of a proverb.

Notwithstanding, many scholars have made several attempts to define proverb in their own ways. Proverbs have been seen as '.. a dynamic mode of discourse with unique identity ... ${ }^{[43]}$. Proverb in another context has also been defined as '.. a traditional, conversational didactic genre with general meaning, a potential free conversational turn, preferably with figurative meaning ${ }^{[39]}$. Another explanation of proverb is 'a unit of meaning in a specific context through which the

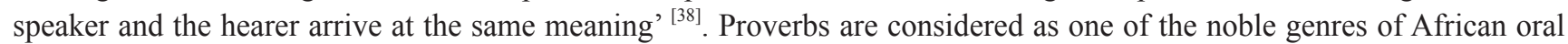
tradition that enjoys the prestige of a custodian of people's wisdom and philosophy of life ${ }^{[49]}$.

By subjecting the above definitions to deductive reasoning, proverbs can best be defined based on specific context of both the speaker and the hearer as well. Therefore, for the purpose of this study, I subscribe to the definition of proverb by Medier: 'Proverb is a short generally known sentence of the folk which contains wisdom, truth, moral, and traditional views in a metaphorical fixed and memorable form and which is handed down from generation to generation, ${ }^{[35]}$.

As a representation of the traditional wisdom, truth and moral lessons to members of a given community, literature on proverbs has been very encouraging as a lot of prominent writers across the globe have written more on it from different perspectives. Some writers captured proverbs as one of the genres of Africa oral Literature stressing on its importance and usage in a particular community: $[20,42,50]$.

Other writers have also worked more extensively on the role and importance of proverbs in the day to day life of a people laying particular emphasis on its usage in various contexts and occasions: $[1,50]$. Proverbs have been used as the medium of fostering intergenerational relationships. Some researchers have also done extensive work on proverbs by focusing on its educational wisdom which has been used as a vehicle of enhancing critical thinking skills of certain people ${ }^{[5,40]}$. The aesthetic value and general wisdom in proverbs cannot be underestimated in this modern era ${ }^{[36,56]}$. Other researchers have also compiled a good number of proverbs for students and others with interest in reading Akan proverbs to get material to read and equip themselves with knowledge ${ }^{[4]}$.

Proverbs play some significant roles and for that matter its' ethno-cultural and social functions cannot in any way be underestimated. A number of scholars have outlined many functions of proverbs some examples of which are stated below: Proverbs promote better understanding of the way of thinking of people, revealing the nature of peoples' mindsets and to 
express both emotional and intellectual attitudes such as sympathy, love, empathy, apology, approval ${ }^{[30]}$. Proverbs also reflect the ethnography of the people and set out their philosophy, morals, social value and their total way of life. Also, proverbs are sometimes used to praise behaviour, warn against defiance, and advise people to refrain from wrong doing. As backbone to the traditions of societies, proverbs are used to demonstrate and buttress the wisdom of the traditional code of conduct. Finally, cross-ethnographically, proverbs provide didactic and moral lessons to humanity and this helps people live their lives in conformity with the societal norms ${ }^{[1,8]}$.

The numerous works on proverbs by the above prominent writers across the globe clearly indicate the high rate of interest researchers have developed in this area of study. Irrespective of many publications and research works proverbs have enjoyed in academia, there are still some shortfalls. One area the numerous researchers have fallen short in their research works particularly in Ghana, is by subjecting proverbs to syntactic analysis, comparing the relative clause formation in the Akan normal sentences to that of relative clause in proverbs to bring out their similarities and differences. This task is what this study seeks to do.

\section{Meaning of relative clause}

Relative clauses are said to be 'embedded / subordinate clauses that typically serve as noun modifiers within an NP structure' ${ }^{[48]}$. Semantically, a relative clause may be characterized as a clause that 'incorporates, as one of its' terms, a nominal which is co-referential with a nominal outside of the clause, ${ }^{[16]}$, cited in [48]. The implication is that it is the modifying clause which constitutes the relative clause but not the whole of the Noun Phrase.

Relative clause modifies a Head Noun ${ }^{[51]}$. What this means is that the relative clause says something more about the Head Noun in a syntactic structure. Even though the relative clause phenomenon exists in almost all the natural languages in the world, yet its formation exists in different forms as found in different syntactic structures. For instance, in English language is a Right Branching Direction (RBD). This simply means that relative clauses are formed at the right of the head noun. In English language, the relative clause is introduced by pronouns such as who, whose, which, where, that ${ }^{[55]}$. The relative clause in English provides sufficient and additional information about the ANP which precedes the R/C in the construction. Studies in relative clause formation is not only unique to Akan alone but has also been studying in various Kwa languages such as Fćngbe ${ }^{[32]}$, Ewe ${ }^{[2]}$, Gã ${ }^{[12]}$, Logba ${ }^{[15]}$ and [29]. Gur languages within the Niger-Congo family also have relative clause in them: Dagbani ${ }^{[27]}$, Gurune ${ }^{[6]}$, Bùlí ${ }^{[26]}$, and Benue-congo. Eg. Yoruba ${ }^{[32]}$.

The phenomenon of the relative clause does not only exit in African languages but other languages such as Japanese, Chinese, Turkish and Hindu ${ }^{[33]}$. Turkish and Hindu languages are all Left Branching Direction (LBD) in which the relative clauses pre-modify the head noun. There are basically two types of relative clauses, thus Internally-Headed Relative Clause and Externally-Headed Relative Clause ${ }^{[3,9,11,23]}$ and [34]. Available literature on relative clause suggests that some languages across the globe have one type of relative clause; Lakhota ${ }^{[55]}$, whereas others also have both as in Japanese language ${ }^{[31]}$. Structurally, the $\mathrm{EHRC}_{\mathrm{S}}$ are relativized outside the relative clause, however, that of the $\mathrm{IHRC}_{\mathrm{S}}$ are also relativized within the relative complement.

\section{Materials and methods}

The data in this study were all collected from various published and unpublished sources. It should be noted with great emphasis that the proverbs selected are a group of proverbs which have relative clauses in their structure. In this regards, purposive sampling method was employed to select the proverbs for this study. In all, twenty-three (23) proverbs were selected for the study. In the case of the Akan normal sentences, examples in the discourse were primary source originating from the native speaker intuitions of the writers.

\section{Results and analysis}

The study has revealed the existence of similarities and differences in the formation of both the Akan Normal Sentence and Akan Proverb Structure as have been illustrated in the various examples. One constituent property both structures share in common is the headless ANP. It has been revealed that, with the headless ANP, the pronominal undergoes a binary mutation in order to account for the headed noun and the relativizer. Both structures also have headed nouns which act as subjects in the sentences they occur. Also, the RES in the RCs in both structures relativize the headed noun which function as subjects structures. Similarly, syntactic dichotomy exists in the lexical positions of the resumptive pronoun in both structures. Thus, whereas the RES in Akan Normal Sentence occurs in the objective case of the relative verb, that of the Akan Proverb Structure also occurs in the subjective case of the relative verb. In terms of form, the resumptive pronoun 
is seen in the Akan Normal Sentence as an independent lexical item whiles in the Akan Proverb Structure, it is seen as a proclitic of the stem it attaches itself to but its presence in the structure does not seem to be an independent lexical item.

\section{Relative clause formation in Akan}

The basic function of the R/C is to throw more light or say something about the ANP. The particle that introduces the Akan R/C is ' $a$ '. This particle has different semantic meanings depending on the particular syntactic slot it occupies in the structure under consideration. The particle 'a' can be used to mean or indicate; which, what where, that, whose, etc. A typical Akan normal sentence containing relative clause is seen in example (1) below.

1. Akwadaa no [a Ama hwee no no] a -wu.

Child DEF [REL Ama beat-PST RES DET] PRF-die.

The child who came here is dead. (FT)

In the above example, "Akwadaa no", (The child), is the head and it constitutes the ANP of the relative clause in the structure. The particle 'a' which introduces the relative cause in the structure is referred to as relativizer in study of syntax. The relative clause is the expression in the brackets and it constitutes the restrictive relative clause. In the other way round, the R / C gives information about the ANP. In this example, the R/C specifically describes the ANP 'The child' or better still throws more light to the ANP 'The child' who came here. Careful syntactic observation of the formation of the Akan relative clause reveals that the ANP $+\mathrm{R} / \mathrm{C}$ will result in the formation of Complex Noun Phrase, which will function as subject in that whole structure.

\subsection{The structure of the Akan relative clause}

2a. Mehyiaa obaa [a Ama hwee no] no.

1SG-meet-PST 1SG-Woman [REL Ama beat-PST RES] EMP.

The woman who was beaten by Ama. (FT)

In example $2 \mathrm{a}$ above, the head noun in the structure 'obaa' comes on the left periphery of the relative clause in the square bracket, 'a Ama hwee no'. The relative clause starts with the relative complementizer, a. This relative complementizer ' $a$ ' introduces the relative clause and for that matter it is the RC marker. The noun 'Ama' in the RC is a complement in the structure: Mehyiaa Ama. The past tense verb 'hwee' is followed by a resumptive pronoun 'no' which is a co-referential copy of the noun, 'obaa'. This co-referential copy agrees in number with the head noun as seen in the sentence. The next lexical item in the structure, "no' is a complementizer determiner in the sentence "Mehyiaa obaa no." which has been calved from sentence $\mathrm{c}$ in $2 \mathrm{a}$ above. In term of function, the NP (Head Noun) + RC + RES (obaa + a Ama hwee no + no) functions as object of the whole sentence 2a, thus, 'Mehyiaa cbaa [a Ama hwee no] no'. Clearly, we see that relativization in example 2a occurs in object position. This makes the above structure SVO. The Akan RC is postnominal type as the head noun precedes the relative clause. Ewe and Gurene dialects spoken in Ghana also have the SVO structural arrangements. The SVO type of structure appears to be the commonest in all human languages ${ }^{[45]}$.

\section{2b. Akwadaa [a odii aduane no] te Nkran}

Child [REL 3SG-eat-PST DET] lives Accra.

The child who ate the food lives in Accra. (FT)

In sentence $2 \mathrm{~b}$ above, the NP (Head Noun) $+\mathrm{RC}$ together functions as the subject in the sentence the whole sentence. The relativization occurs in the subject position of the sentence. In the structure above, the relativization occurs in the subject position of the sentence. Then also, in the complement clause, the resumptive pronoun $\mathrm{c}$ is in the subject position of the simple sentence in the clause, thus, 'cdii nkonim.' The syntactic position of the Akan R/C is seen to be in conformity with the universal pragmatic principle that shifts long complex information late in the clause ${ }^{[45]}$.

\subsection{The Akan extra posed relative clause}

As illustrated in the above examples of the construction of the R / C in Akan, the R / C has been positioned adjacent to the Head Noun as seen in example $1 \mathrm{a} \& 2 \mathrm{~b}$. This phenomenon manifests as one of the features of all noun modifiers which occurs in the SVO syntactic structure. There is however sharp contrast to the above phenomenon as there are some kind of syntactic constructions as in the case of Akan where the relative clause is postposed to the end of the main clause (objective case). Extra posed is the name ascribed to such relative clauses ${ }^{[46]}$. See examples $3 a \mathrm{a} b$ for more clarification.

\section{3a. Papa no to-っ kaa no [a a-see no].}

Man DEF buy-PST car DEF [REL PRF-condemn DET].

The man bought the car which has condemned. (FT)

3b. Yaw fa-a nwoma no [a na $\varepsilon$-da ho no]. 
Yaw take-PST book DEF [REL FOC 3SG there DET].

Yaw took the book which was lying there. (FT)

From the examples $3 \mathrm{a} \& \mathrm{~b}$ above, it can be deduced that $\mathrm{R} / \mathrm{C}$ are entirely different from that of examples $2 \mathrm{a} \& \mathrm{~b}$. This happens as a result of the fact that, the two syntactic environments are in sharp contrast considering their relational structures. For instance, in example $2 \mathrm{a} \& \mathrm{~b}$ the R/C together with the ANP functions as the subject of the verb in each of the sentences whereas that of $3 \mathrm{a} \& \mathrm{~b}$ describes the preceding noun in the structure.

\subsection{Stacking of relative clause}

In Akan, there are some relative clauses which are stacked within the same sentence in relativization. In such situation, there could be several relative clauses in a construction which modify a single antecedent noun phrase. This type of construction looks quite similar to that of the serial verb construction which remains a phenomenon in Akan language. See example $4 \mathrm{a} \& \mathrm{~b}$ below.

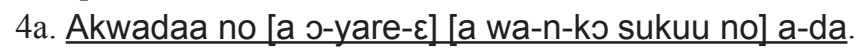

Child DEF [REL 3SG- SICK-PST] [REL 3SG-NEG-go school FOC] PRF-sleep.

The child who was sick and did not go to school is asleep. (FT)

4b. Maame no [a o-ba-a ha] [a o-fa-a atade no] a-da.

Woman DEF [REL 3SG-come-PST here] [REL 3SG-take-PST dress DET] PRF-sleep.

The woman who came here and took the dress has come. (FT)

In examples $4 \mathrm{a} \& \mathrm{~b}$ above, it is noticeably clear that each example has in it two relative clauses which modify the single NAP in each structure. Observation can also be made from the examples that the relative clauses in each sentence are in direct sequence of each other. The construction does not only occur in Akan conversational discourse but there are also some instances where it manifests itself in the written discourse too.

\subsection{Relativizers and their constraints}

The relativizers and their constraints are all key syntactic properties of Akan relative clauses. In section 4.2, we had a look at Akan relative clause formation. From example 1a, we learned that the R/C in Akan is introduced by a particle ' $\mathrm{a}$ ' which can occur in different syntactic environments to perform different semantic functions in the sentence. In Akan language, the particle ' $\mathrm{a}$ ' is an obligatory lexical element in the relative clause. This same particle ' $\mathrm{a}$ ' is used to connote both singularity and plurality taking into account the semantic of the structure in which it has been used. See examples $5 \mathrm{a}$ \& $\mathrm{b}$ below.

5a. O-baa no [a o-ba-a ha no] a-da.

3SG-woman DET [REL 3SG-come-PST here FOC] PRF-sleep.

The woman who came here is asleep. (FT)

5b. Akwadaa no [a o-di-i aduane no] yare.

Child DEF [REL 3SG-eat-PST food FOC] sick.

The child who ate the food is sick. (FT)

The obligatory phenomenon of the Akan relativizer simply agrees with the claim made by Saah ${ }^{[47]}$ that the relative complementizer is compulsory because the deletion or omission of the relativizer in the above constructions would have rendered the constructions ungrammatical.

The second feature of the Akan relativizer is that, it does not change its shape in order to agree in number and in class with the Head Noun. See examples $6 \mathrm{a} \& \mathrm{~b}$ below.

6a. M-baa no [a wo-ba-a ha no] a-ye ade.

PL-woman DEF [REL 3PL-come here CFM] PRF-COP well.

The women who came here have done well. (FT)

6b. J-baa no [a o-ba-a ha no] a-di-di.

3SG-woman DEF [REL 3SG-come-PST here CFM] PRF-eat-eat.

The woman who came here has eaten. (FT)

In example $6 a$, the head is plural but in $6 \mathrm{~b}$, the head is singular. Regardless of the singularity or the plurality of the head in the above constructions, the relativizer still remains unchanged. Saah ${ }^{[47]}$ has confirmed this by stating that 'whether the relativized NPs are singular or plural, the relative complementizer does not change in shape and form. This phenomenon also exists in Guren $\varepsilon$ one of the Northern dialects spoken in Ghana ${ }^{[7]}$.

\subsection{The clause final marker}

In constructing the Akan relative clause, the particle [no] may play dual function syntactically; thus (1) as a marker 
of definiteness, and (2) as a clause final marker of subordination in the relative clause. In Akan, for any sentence to be grammatically acceptable, the particle [no] which may be occupied by a noun phrase such as numerals or pronominal should not be omitted from the construction. Dzemeshie ${ }^{[18]}$ makes reference to the particle [no] in the relative clause typology as the clause final marker (CFM). In Akan, this phenomenon also exists as a unique relationship between the Head Noun and Clause Final Marker. It is observed in the relationship that the [no] forming part of the ANP and the CFM [no] have the same form. Syntactically, we can see that the [no] morpheme marks both definiteness and subordination as illustrated in examples $7 \mathrm{a} \& \mathrm{~b}$ below.

7a. Papa no [a o-ko-o ho no] a-hwe ase.

Man DEF [REL 3SG-go-PST CFM] PRF-fall down.

The man who went there has fallen down. (FT)

7b. Osuani no [a o-ton nwoma no] a-ba ha.

Student DEF [REL 3SG-sell book CFM] PRF-come here.

The student who sells the books has come here. (FT)

One very striking thing to note in the above examples is that even if the ANP is replaced with another form as seen in $8 \mathrm{a} \& \mathrm{~b}$, the CFM still remains unchanged in the structure.

8a. Aduane bi [a me-di-i $\varepsilon$ no] $n-y \varepsilon d \varepsilon$.

Food DET [REL 1SG- eat-PST CFM] NEG-COP delicious.

The food that I ate is delicious. (FT)

8b. Ntoma bi [a me-to-ee no] ye fe.

Cloth DET [REL 1SG-buy-PST CFM] COP beautiful.

The cloth which I bought is beautiful. (FT)

\subsection{The resumptive pronoun}

The relative clause construction in some languages seeks to retain a pronominal within the $\mathrm{R} / \mathrm{C}^{[51]}$. This pronominal is known as the resumptive pronoun. It occupies the syntactic position of the referent in the relativization. In Akan, this resumptive pronoun is a phenomenon in the formation of some relative clauses. This RES usually precedes the verb within the R / C. Saah ${ }^{[47]}$ outlined some transitive verbs such as 'kum'----kill, 'hyia'----meet etc. which accommodate the RES in the $\mathrm{R} / \mathrm{C}$ construction. See data $9 \mathrm{a}, \mathrm{b} \& \mathrm{c}$. below.

9a. Aboa no [a Ama hunu-u no no] a-da.

Animal DEF [REL Ama see-PST RES FOC] PRF-sleep.

The animal which Ama saw is asleep. (FT)

9b. Akwadaa no [a Yaw hwe-e no no] a-wu.

Child DEF [REL Yaw beat-PST RES FOC] PRF-die.

The child that Yaw beat is dead. (FT)

9c. *Akwadaa no [a Yaw hwe-e ф no] a-wu.*

Child DEF [REL Yaw beat-PST ф FOC] PRF-die.

The child that Yaw beat is dead. (FT)

In Akan, the resumptive pronoun is a necessary grammatical item which is used to relativize the subject in a sentence; occurrence which is cross-linguistically unusual. Since there is no RES, the subject (Head Noun) is not relativized. In sentence $9 \mathrm{c}$ above, the absent of the co-referential copy in the relative clause makes it difficult to identify the child who was beaten by Yaw. For easy identification, the RES must be accounted for in the relative clause as in sentence (9a \& b).

\subsection{Similarities of relative clause formation in Akan normal sentences and proverb structure}

This section discusses the similarities of the relative clause formation in both Akan normal sentence and that of Akan proverb structure with respect to their relational and the constituent structures.

The first observation is that there is the absence of Head Noun Determiners in both structures. This is evidently manifested in the formation of Overt Antecedent Noun Phrase in both structures below.

\subsubsection{Normal sentence structure}

10a. Abaayewa ф [a o-kum-m aboa no] a-ba.

Girl ф [REL kill-PST DET] PRF come.

The girl who killed the animal has come. (FT)

10b. Onipa ф [ a s-wia-a ntoma no] nnue.

Person क RE L 3SG-steal-PST cloth DET woe.

Woe betides the person who stole the cloth. (FT) 


\subsubsection{Akan proverb structure}

11a. Sisie ф [a [-wo-o ba no] na [-turu no.

Waist क [REL 3SG-born-PST child FOC] 3SG-carry DET.

A waist that brought forth a child carries it. (FT)

11b. Anamm]n क [a a-di kan no] ne to y [tonna.

Foot step $\phi$ [REL 3SG-eat first DET] FOC catch is difficult.

Foot step that is ahead of you is difficult to be at par with. (FT)

As has been observed in the above structures, examples $10 \mathrm{a} \& \mathrm{~b}$ represent the normal sentences whereas examples $11 \mathrm{a} \& \mathrm{~b}$ represent the proverb structures. What brings about the similarities in the above structures is that, there is presence of null head noun determiners in both structures. In the normal sentences, the presence of the head noun determiners will still render the sentences meaningful only when we want to show definiteness but in the context of generalization, it will always be omitted as seen in examples $10 \mathrm{a} \& \mathrm{~b}$ above. The phenomenon is in agreement with the assertion made by [37] that human NPs disfavour the enclitic 'no' in many occasions. What has accounted for the omission of the head noun determiners in examples $11 \mathrm{a} \& \mathrm{~b}$ in the proverb structures is that, proverb being a communal property, has a universal truth and as such it does not point to a particular object or thing ${ }^{[56]}$ despite the fact that definite NPs do favour the enclitic 'no'. Should it happen that way, the universality of its truth will be missing entirely.

Another observation is that both structures can form their relative clauses in the objective case of the structures (extra position $\mathrm{R} / \mathrm{C}$ ) as found in examples $12 \mathrm{a} \& \mathrm{~b}$ and $13 \mathrm{a} \& \mathrm{~b}$ below. The common phenomenon here is that, the $\mathrm{R} / \mathrm{Cs}$ do not occur in the subjective cases but the syntactic positions of its occurrences are that they occur at the post positions of the objects in the structures under consideration to modify the immediate noun phrase. This intensifies the argument by Fox ${ }^{[21]}$ that the RC can occur 'at the right periphery where it merged'.

\subsubsection{Normal sentence structure}

12a. O-wudi-ni no kum-m Akwadaa no [a na o-gyina ho no].

3SG-kill-3SG DEF KILL-PST child DET [REL FOC 3SG-stand there DET].

The killer killed the child who was standing there. (FT)

12b. D-koromfoo no wia-a maame no [a na w-a-da no].

3SG-thief DEF steal-past woman DET [REL FOC 3SG-PRF-sleep DET].

The thief stole from the woman who was asleep. (FT)

\subsubsection{Akan proverb structure}

13a. O-h]hoo na o-we a-koko [a n'a-ni a-bo].

3SG-strange person FOC 3SG-chew 3SG-cock [REL 3SG -POSS-eye PRF-crack].

It is a stranger that eats a one eyed cock. (FT)

13b. Onipa n-nka [dec w-a-hunu].

Man NEG-say [PRN 3SG-PRF-see].

Man does not say what he has seen. (FT)

Another common phenomenon in the structures is the presence of the resumptive pronoun as seen in examples 14a \& $\mathrm{b}$ and $15 \mathrm{a} \& \mathrm{~b}$ below. Both structures display the retention of resumptive pronoun in all of the structures. The reason for the presence of the RES in any of the above sentences is that the RES relativizes the head nouns used to function as subject in any of the sentences $(14 \mathrm{a} \& \mathrm{~b})$ and $(15 \mathrm{a} \& \mathrm{~b})$ below. The resumptive pronoun no relativizes the subjects 'Osuani no' and 'Abofra no' as in $14 \mathrm{a} \& \mathrm{~b}$. In like manner, the proclitics $\mathrm{c}$ and $\varepsilon$ Abofra and Sotoro as in examples $15 \mathrm{a} \& \mathrm{~b}$. The presence of the RES confirms McCracken ${ }^{[37]}$, assertion that the RES helps in the relativization of the head noun in the structure.

14a. Osuani no [a tikya Kofi hwee no no] yare.

Student DEF [REL teacher Kofi beat-PST RES DET] sick.

The student who was beaten by the teacher Kofi is sick. (FT)

14b. Abofra no [a ne papa fre- $\varepsilon$ no no] a-m-ma.

Child DEF [REL POSS father call-PST RES DET] 3SG-NEG-come.

The child who was called by the father did not come. (FT)

\subsubsection{Akan proverb structure}

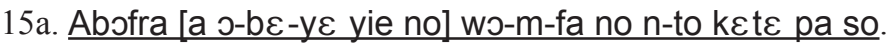

Child [REL RES-FUT-COP well DET] 3PL-NEG-take F OC NEG-lay mat good on.

A child that will be a successful person will not be put on a good mat. (FT)

15b. Sotoro [a $\varepsilon$-b [n wos no] wo-gye no ntem. 
Slap [REL RES-near you DET] 2PL-receive FOC early.

A slap closer to you is received early. (FT)

Moreover, Akan normal sentence and proverb structure show the formation of covert ANP (headless) which happens to be a pronominal. In the sentences below $(16 \mathrm{a} \& \mathrm{~b})$, none of the relative clause is nominalized and so in the absence of the Headed Noun there should be a pronominal representation of the head in the relativized position ${ }^{[33]}$. This pronominal, in Akan, must undergo what I term as 'binary mutation' in order to account for the head noun and the relativizer as seen in examples $(17 \mathrm{a} \& \mathrm{~b})$ respectively.

\subsubsection{Akan normal sentence}

16a. [Dee o-wo aso no] ntie.

Onipa a 3SG-have ear DET listen.

The person that has ear should listen. (FT)

16b. [Dee o-ba-a ha no] na o-fa-a sika no.

\}

Onipa a 3SG-come-PST DET FOC 3SG-take-PST money DET.

The woman who came here took the money. (FT)

\subsubsection{Akan proverb structure}

17a. [De o-foro dua pa] na ye-pia no.

(1)

Onipa a 3SG-climb tree good FOC 3PL-push DET.

The person that climbs a good tree needs a push. (FT)

17b. [Re[ ]-b[-bo wo m-ma-e[a] wo-se obiara n-tumi wo.

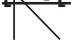

Onipa a 3SG-FUT-beat you NEG-come-PST 2PL-say none NEG-can you.

If person that can beat is not around you say nobody can beat you. (FT)

In examples $18 \mathrm{a} \& \mathrm{~b}$ and $19 \mathrm{a} \& \mathrm{~b}$ below it is observed that both structures have the same clause final markers. The CFM no in both structures has sameness of shape and form as seen from the examples below.

\subsubsection{Akan normal clause formation}

18a. Akwadaa [a]-fa-a sika no] a-tu kwan.

Child REL 3SG- take-PST DET PRF-uproot road.

The child who took the money has travelled. (FT)

18b. \}-kra [a]-wia-a nam no] a-dwane.

3SG-cat [REL 3SG-steal-PST meat DET] PRF-run away.

The cat that stole the meat has run away. (FT)

\subsubsection{Clause formation in the Akan proverb}

19a. Kwae $[$ [a a-gye wo] no] ye-m-fr [no kwae [-wa.

Forest [REL PRF-save you DET] 3PL-NEG-call FOC forest- small.

A forest that has saved is not considered as small forest. (FT)

19b. Nsa [a ye-de hy [nkuu no] [-no ara na y [-de te[.

Hand [REL 3PL-FOC fill pomade DET] 3SG-FOC EMP FOC 3PL-FOC scoop.

A hand that is used to fill pomade is the same hand that is used to scoop it. (FT)

\section{Discussion}

\subsection{Differences in relative clause formation in akan normal sentences and proverb structure}

In this section, the discussion focuses on the syntactic differences which exist between the two structures in relation to some of their relational and constituent structures. The Akan normal sentences as seen in examples 20a \& b and 21a \& b possess Head Noun Definiteness 'no' which follows the Antecedent Noun Phrase in any of the sentences whereas that of proverb structures in $21 \mathrm{a} \&$ b do not have the Head Noun Determiners. The enclitic 'no' as in $20 \mathrm{a} \&$ b clearly defines the NP in each sentence.

\subsubsection{Akan normal sentence}

20a. Abaayewa no [a okum-m aboa no] a-ba.

Girl DEF [REL kill-PST DET] PRF come. 
The girl who killed the animal has come. (FT)

20b. Onipa no [a o-wia-a ntoma no] nnue.

Person DEF [ RE L 3SG-steal-PST cloth DET] woe.

Woe betides the person who stole the cloth. (FT)

\subsubsection{Akan proverb structure}

21a. Sisie ф [a $\varepsilon$-wo-o ba no] na $\varepsilon$-turu no.

Waist o REL 3SG-born-PST child FOC 3SG-carry DET.

A waist that brought forth a child carries it. (FT)

21b. Anammon $\phi$ [a a-di kan no] ne to ye tonna.

Foot step $\$$ [REL 3SG-eat first DET] FOC catch is difficult.

Foot step that is ahead of you is difficult to be at par with. (FT)

As outlined in examples 20a \& b and 21a \& b above, each ANP 'Abaayewa' and 'Onipa' is followed by the DEF 'no'. Notwithstanding, the Head Noun Phrase in Akan proverb structure in examples 21a \& b do not accommodate any HND. Syntactically, it is classified as null determiner HNP. Unlike Akan normal sentence, Akan proverbs containing relative clauses do not come with definiteness because proverbs are supposed to be communal property which also hold universal truth as have always been the case.

Secondly, another differentiation made about the two structures is the Clause Final Markers as found in examples 22a \& $\mathrm{b}$ and 23a \& b. The clausal elements in 22a \& b have the DEF 'no' as the CFMs whiles that of 23a \& b also maintain ' $a$ ' as the CFMs in the proverb structures. A sharp contrast is seen in the structures. We observe a determiner 'no' in examples $22 \mathrm{a} \& \mathrm{~b}$ as CFM whiles a conjunction ' $\mathrm{a}$ ' is used as the CFM in examples $23 \mathrm{a} \& \mathrm{~b}$ respectively. The presence and the absence of the CFM 'no' has to do with the definiteness of the preceding noun as in 22 a \& b. In 23 a \& b, the definiteness is not applicable to each of the nouns ending the relative clause, for proverbs are treated as specialized genre. See the examples below.

\subsubsection{Clause final marker in Akan normal sentence}

22a. Aberantec no [a o-hye-e afuo no] a-dwane.

Gentleman DEF [REL 3SG-burn-PST DET] PRF-run away.

The gentleman who burnt the farm has run away. (FT)

22b. Ob] foo no [a o-kum-m aboa no] a-ba fie.

Hunter DEF [REL 3SG-kill- PST animal DET] PRF-come home.

The hunter who killed the animal has come home. (FT)

\subsubsection{Clause final marker in proverb structure}

23a. Ahina [a ye-de ko nsuo] bo a na a-see.

Pot [REL 2PL-COP go water] break CONJ FOC PRF-destroy.

If a pot that is used to fetch water breaks then it is destroyed. (FT)

23b. Yadec [a $\varepsilon$-be-ku wo] bo wo a wo-n-kae hwee.

Ailment [REL 3SG-FUT-kill you] you CONJ 2SG-NEG-nothing.

If an ailment that can kill you hits you, you don't remember anything. (FT)

Another striking revelation is that the resumptive pronouns assume different syntactic positions in Akan Normal Sentences and Akan Proverb Structures as seen in examples 24a \& b and 25a \& b. As critically observed in the Akan Normal Sentences, the RES occurs in the accusative position of the relative verb while that of the Akan Proverb Structures occurs in nominative position of the relative verb. In terms of structural relation, the RES in $24 \mathrm{a} \& \mathrm{~b}$ functions as the object of the relative verb but that of $25 \mathrm{a} \& \mathrm{~b}$ also function as subject of the relative verb of the structure.

Another striking thing to consider is the nature or the shape and form of the RES in structures under consideration. Thus, whiles the RES 'no' in examples $24 \mathrm{a} \& \mathrm{~b}$ is an independent lexical item in the structures, that of $\underline{\varepsilon}, \underline{\rho}$ and $\underline{\varepsilon}$ as found in examples $25 \mathrm{a} \& \mathrm{~b}$ is independent proclitic though but not a complete and acceptable lexical item as far as Akan structural analysis is concerned.

\subsubsection{Resumptive pronoun in akan normal sentence}

24a. Awuraa no [a wo-fre- $\varepsilon$ no no] a-ba.

Lady DEF [REL 2SIG-call-PST RES DET] PRF-come.

The lady you call has come. (FT)

24b. Aboa no [a Kofi kum-m no no] yare.

Animal DEF [REL Kofi kill-PST RES DET] sick. 
The animal Yaw killed is sick. (FT)

\subsubsection{Resumptive pronoun in akan proverb structure}

25a. Yare $\varepsilon$ [a $\varepsilon$-b [-ku woo no] n-nim aduro.

Ailment [REL RES-FUT-kill you DET] NEG- know medicine.

An ailment that will kill you knows no medicine. (FT)

25b. J-baatan [a o-wo-o ne ba no] na o-nim abadaee.

3SG-Nursing mother [REL RES-born-PST POSS child DET] FOC 3SG-know love.

It is the nursing mother that has love for the child. (FT)

Another striking difference per the consideration of both structures is the staking of the relative clause. This phenomenon remains a feature in the Akan Normal Sentences as seen in examples (26a \& b). However, that kind of phenomenon does not in any way exist in Akan Proverb Structures as can be observed in examples 26a \& b below.

\subsubsection{Staking of the relative clause in Akan normal sentence}

26a. Owura no [a o-hwe-e o-baa no] [a wo-bo-o no ka no] a-di hene.

Gentleman DEF [REL 3SG-beat-PST 3SG-woman DET] [REL 2PL-kick-PST FOC cost FOC] P install chief.

A gentleman who beat the woman and cost was awarded against him has been installed a chief. (FT)

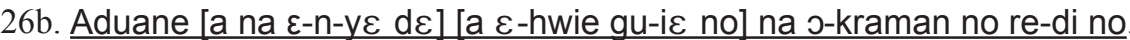

Food [REL FOC 3SG-NEG-delicious] [REL 3SG-pour- PST DET] 3SG-dog DET PROG-eat FOC.

The food which was not delicious and poured down is being eaten by the dog. (FT)

\section{Conlusion}

The paper sought to find out the similarities and differences in the relative clause formation in Akan normal sentence and proverb structure. At the end of the analysis, the following facts were established. Similarities exit in both structures in terms of the presence of RES. Relative clauses occur at the right periphery of the structures. A Pronominal which undergoes a binary mutation to account for the head and relativizer is also seen in both structures. In terms of the differences, the CFM 'no' shows the definiteness of the preceding noun in the Akan normal clause whiles there is absence of such CFM in the proverb structure. It has been also established that differences exist in the syntactic positions of the RES in both structures. From the above, it is indeed obvious that similarities and dichotomy exist in both structures. The existence of similarities and difference in RC formation in both Akan proverbs and Akan normal sentences has significant implications on the Akan language and its usage. The findings from the study have enlightened the users of the language to appreciate the formation of RCs in proverbial structures and normal sentences in Akan and to help them draw structural correlations between the two structures as indicated in $24 \mathrm{a} \& \mathrm{~b}, 25 \mathrm{a} \& \mathrm{~b}, 26 \mathrm{a} \& \mathrm{~b}$ etc. Finally, the findings from the study would also help the language users to fully understand the structural sameness and dichotomy of both the Akan proverb structure and Akan normal sentence with regards to RC formation in the two different structures. 


\section{Abbreviation}

$\begin{array}{ll}\text { FT } & \text { Free translation } \\ \text { REL } & \text { Relativizer } \\ \text { R/C } & \text { Relative clause } \\ \text { COP } & \text { Copula verb } \\ \text { POSS } & \text { Possessive pronoun } \\ \text { DET } & \text { Determiner } \\ \text { 3PL } & \text { Third person plural } \\ \text { PRF } & \text { Perfect tense } \\ \text { PST } & \text { Past tense verb } \\ \text { NEG } & \text { Negation } \\ \text { FUT } & \text { Future tense } \\ \text { ANP } & \text { Antecedent Noun Phrase } \\ \text { CANP } & \text { Covert Antecedent Noun Phrase } \\ \text { OANP } & \text { Overt Antecedent Noun Phrase } \\ \text { HND } & \text { Head Noun Determiner } \\ \text { RES } & \text { Resumptive Pronoun } \\ \text { PRN } & \text { Pronominal } \\ \text { CONJ } & \text { Conjunction } \\ \text { PROG } & \text { Progressive tense } \\ \text { RBD } & \text { Right branch direction } \\ \text { LBD } & \text { Left branch direction } \\ \text { DEF } & \text { Definiteness } \\ \text { EMP } & \text { Emphatic Pronoun } \\ \text { ANS } & \text { Akan Normal Sentence } \\ \text { ANSs } & \text { Akan Normal Sentences } \\ \text { APS } & \text { Akan Proverb Structure } \\ \text { APSs } & \text { Akan Proverb Structures } \\ \text { 2SG } & \text { Second Person Singular } \\ 2 \text { PL } & \text { Second Person Plural } \\ 3 S G & \text { Third Person Singular } \\ 3 P L & \text { Third Person Plural } \\ * & \text { Ungrammatical Sentence } \\ \text { p } & \text { Null } \\ & \end{array}$

\section{References}

[1] Agyekum, K. Akan proverbs and aphorisms about marriage. Research Review. 2005; 27(2): 1-24.

[2] Ameka, F. How discourse particle mean. The case of the Ewe "terminal particles". Journal of African Languages and linguistics. 1991; 12(2): 143-170.

[3] Andrew, A. Relative clauses. Language typology and syntactic description. In Timothy Shopen (ed). 2007; 2(2): 206236.

[4] Appiah, P, Appiah, K. A., Agyemang-Duah, I. Bu me B[: Akan Proverbs. Accra: Centre for Intellectual Renewal. 2000.

[5] Asimeng-Boahene, L. Educational wisdom of African oral literature: African proverbs as vehicle for enhancing critical thinking skills in social studies education. International Journal of Pedagogies and Learning. 2009; 5(3): 59-69.

[6] Atintono, A. S. A Functional Analysis of Grammar, Relative Clause. Winneba, Ghana: University of Education; 2003.

[7] Atintono, A., S. A functional analysis of the relative clause. Published in An insight into teaching and learning of languages in contact in West Africa. 2003.

[8] Bascom, W. The Yoruba of Southwestern Nigeria. Long Grove: Waveland Press, Inc; 1984.

[9] Bianchi, V. Headed relative clause in generative syntax (Part I \& II). 2002.

[10] Boadi, L., A. Interrogatives, complementation and relativization. Three major Syntactic Structures in Akan. Accra: Black Mask Limited; 2005.

[11] Bodomo, A., Hiraiwa, K. Relativization in Dagaare and its typological implications, Left-headed but internally headed. 
Lingua. 2010; 120(4): 953-983. Available from: doi: https//doi,org/10.1016/j.2009.06.008.

[12] Dakubu, M.E.K. Contrast in context: topic, focus and definiteness in Ga. Journal of West African Languages. 1992; 22(2): 3-16.

[13] Dakubu, K., M., E. The Languages of Ghana. London: Kegan Paul International Limited; 1998.

[14] Dolphyne, E., A. The Akan (Twi-Fante) Language: Its Sound systems and Tonal Structures. Accra University Press; 1998.

[15] Dorvlo, K. A grammar of Logba (Ikpana). Ph.D. thesis, Leiden University; 2008.

[16] Downing, J. Linguistic awareness, English orthography and reading instruction. Journal of Reading Behaviour $x, i$. $1978 ; 378$.

[17] Downing, A., Philip, L. English Grammar. A university course (2 $2^{\text {nd }}$ ed). London: Routledge; 2006.

[18] Dzemeshie, A., K. Relativation in Ewe. M. A Thesis. Bloomington: Indiana University; 1983.

[19] Finnegan, R. Oral Literature in Africa. New York: Oxford University Press; 1970.

[20] Finnegan, R. Oral Literature in Africa (2nd. ed). Cambridge, UK: Open Book Publishers; 2012.

[21] Fox, D. Antecedent-contained deletion and the copy theory movement. Linguistic Inquiry. 2002; 33: 63-69.

[22] Ghana Statistical Service. Population and Housing Census: Summary Report of Final Results. Accra, Ghana: GSS. 2012.

[23] Cinque. G. Typological Studies: Word Order and Relative Clause. NY: Routledge; 2013.

[24] Givon, T. Syntax. Amsterdam: John Benjamins; 2001.

[25] Halliday, M., A., K. An Introduction to Functional Grammar (2 ${ }^{\text {nd }}$ ed). London: Arnold; 1994.

[26] Hiraiwa, K. Predicate cleft in bùlí: Categories and phases. Linguistic Analysis. 2002; 32(3-4): 544-583.

[27] Inusah, A. R. Patterns of relative clauses in Dagbanli. SAGE Open. 2017; 7(1): 215824401769201.

[28] Kindstrand, J.F. The Greek concept of proverbs. Eranos. Acta Philologica Suecana Uppsala. 1978; 76(2): 71-86.

[29] Korsah, S. Pronouns and clausal determiners. Issues in Kwa Syntax. Ph. D. thesis, Universitat Leipzig; 2017.

[30] Kudadjie, J., N. Ga and Dangme Proverbs: For Preaching and Teaching. Accra: Asempa Publishers; 1996.

[31] Kuroda, S.Y. Pivot independent (eds.) relative clause in Japanese. In S.-Y Japanese syntax and semantics. Dordrecht: Kluwer Academic publisher; 1992. p.114-174. Available from: doi: https://doi.org/10. 1075/ jpcl. 13.1.04lef.

[32] Lefebvre, C. AGR in languages without person and number agreement. The case of the clausal determiner in Haitian and Fon. Canadian Journal of Linguistic. 1992; 37: 137-156.

[33] Lehmann, C. On the typology of the relative clauses. Annus Publication; 1986.

[34] Lehmann, C. Der Relativsatz. Tübingen. Germany: Gunter Narr Verlag; 1984.

[35] Mieder, W. Proverbs: A handbook. Greenwood Publishing Group; 2004.

[36] Mieder, W. Proverbs are never out of season: Popular wisdom in the modern Age. Oxford: Oxford University Press; 1993.

[37] McCracken, C. Relative clauses in Asante Twi. Rice Working Papers in Linguistics. 2013; 4.

[38] Mollanaza, H. Principles and methodology of transmission. Tehran: SAMT; 2001.

[39] Norrick, N., R. How proverbs mean? Semantic studies in English proverbs. Amsterdam: Mouton; 1985.

[40] Oduaran, A., Oduaran, C. African proverbs as a medium of fostering intergenerational relationships and communication in the Niger Delta, Nigeria. African and Asian Studies. 2006; 5 (2): 215-229.

[41] Oduro, I. \}be Ho Mpensempensenmu a\} gyina Ckasa Mmara so. Unpublished. 2015.

[42] Okpewho, I. African Oral Literature: Background, Character, and Community. Bloomington: Indiana Univ. Press; 1992.

[43] Omoera, O.S., Inegbebo, B. O. Context of usage and aesthetics of selected proverbs from Southern Nigeria. Journal of Language, Technology \& Entrepreneurship in Africa. 2013; 4(1): 16-30.

[44] Opoku, A. Hearing and Keeping Akan Proverbs. Accra: Asempa Publishers; 1997.

[45] Payne, T., E. Describing Morpho-Syntax: A Guide for Field Linguistics. Cambridge University Press; 1997.

[46] Quirk, R., Green Baum, S. A University Grammar of English. London: Longman Publication; 1973.

[47] Saah, K. K. Relative clause in Akan. Department of Linguistics. University of Ghana, Legon; 2009.

[48] Saah, K. K. Relative clause in Akan. Topics in Kwa Syntax. Springer Dordrecht; 2010. p.91.

[49] Ssetuba, I. The hold of patriarchy: An appraisal of the genda proverb in the light of modern gender relations. A paper of Cairo Gender Symposium. 2002. p.7-10.

[50] Sumner, C. Oromo Wisdom Literature, 1: Proverbs, Collection and Analysis. Addis Ababa: Gudina Kumsa Foundation; 1995.

[51] Tallerman, M. Understanding Syntax. Sydney: Arnold; 1998.

[52] Thompson, G. Introducing Functional Grammar $2^{\text {nd }}$ edn. London: Arnold; 2004.

[53] Van, V. D. R. An Introduction to Syntax. United Kingdom: Cambridge; University Press; 2001.

[54] Wiredu, J. F. Organized English Structure. Accra: Academic Publication Limited; 2009. 
[55] Williamson, J. An indefiniteness restriction for relative clause in Lakhota. The Representation of (in) Definiteness. Cambridge, MA: MIT Press; 1987; 168-190.

[56] Yankah, K. The proverb in the context of Akan rhetoric: a theory of proverb praxis. New York: Peter Lang. Publishing Inc; 1989. 